\title{
Davanil Rares:
}

U.K. NOTICE REQUIR

LONDON-A prestigious and influential body, the Royal Commission on Environmental Pollution, has proposed tough new rules for public disclosure of information about planned releases of genetically engineered organisms (GEOs) into the environment. The Commission, which takes a much wider view of its role than the title suggests, was established as an independent body in 1970 to advise the U.K. government on the adequacy of research on, and possible future dangers to, the environment. Its latest report will have a major impact on imminent new British legislation on deliberate release

If, as seems likely, the government accepts the Commission's proposals, both trial releases and the sale and supply of products will be permitted only if they are licensed jointly by the Secretary of State for the Environment and the Health and Safety Commission (HSC). There will also be a register of those authorized to release GEOs_-with both registration and licensing to be done on the recommendation of a new national "Release Committee." Advising both the

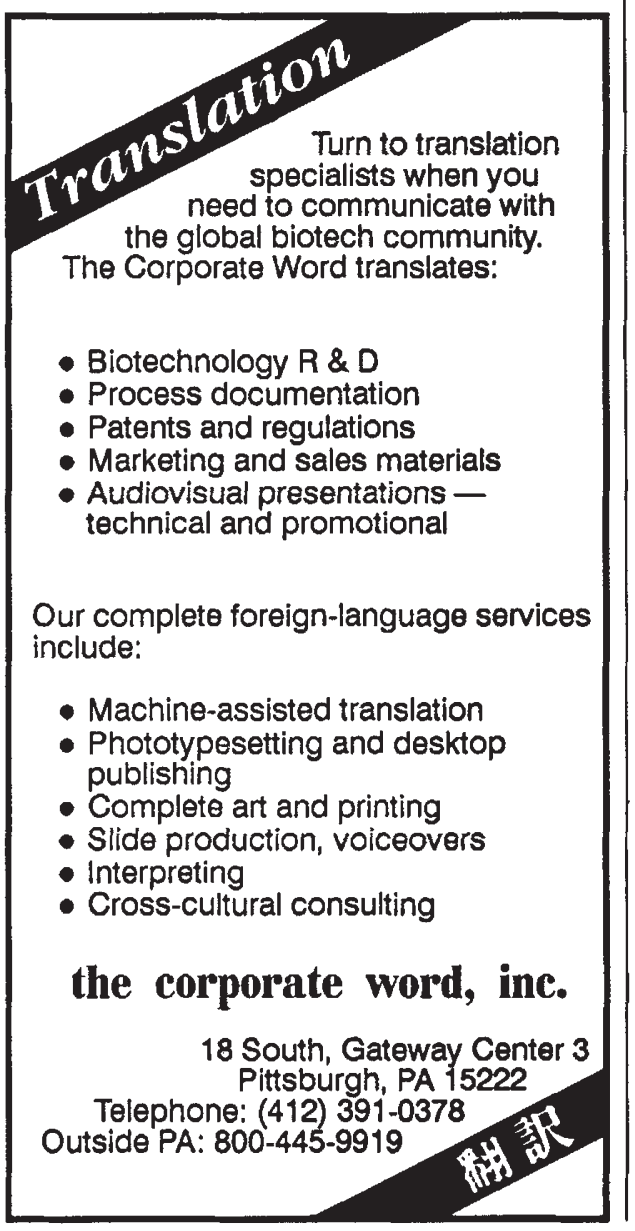

Environmental Secretary and the HSC, this committee will be reconstituted from a subcommittee of the present Advisory Committee on Genetic Manipulation. Individuals, companies, and institutes disseminating organisms without a license, or failing to comply with conditions attached to a license, will incur "substantial penalties."

The Commission, chaired by Cambridge University chemist Lord Lewis, says that persons and organizations applying for licenses to carry out field trials with GEOs should be required to announce their proposals through advertisements in the local press serving the area of intended release. Anyone seeking a license to sell or supply a GEO-as or in a commercial product-would have to place an advertisement in a nationally distributed newspaper as well as a notice in the London Gazette. Members of the public could then protest or send comments to the licensing authority within 30 days. Moreover, "the applicant, and anyone who has made such representations, should subsequently receive a copy of the recommendation made by the Release Committee and be given the opportunity to make representations" again before a final decision is taken. There should also be a publicly available register of both applications and authorized releases, including every applicant's name and address,

\section{OSED}

and particulars of the organism, test site, and purpose of release.

Lord Lewis and his colleagues acknowledge that they are recommending a degree of public access to information that goes well beyond that allowed for most other products, and that some of this information could be of value to competing individuals and companies. They urge that during discussions on biotechnology patents-currently taking place under the auspices of the World Intellectual Property Organisation (Geneva)-a "regime of intellectual property rights should be developed which provides sufficient protection to enable the release of adequate information to the public, without undermining the commercial viability of the development and thereby damaging the incentive for innovation."

The Royal Commission opposes the European Commission's recent proposal that, once a GEO-containing product has been approved for release in one country, it should not be restricted in any other. Reflecting a long-standing disagreement between Great Britain and continental Europe over industrial effluent discharges, the report argues that a proposed release must always be considered in relation to a particular environment, and that a release acceptable in one locality may be unacceptable elsewhere.

-Bernard Dixon

\section{carme EIIIIT

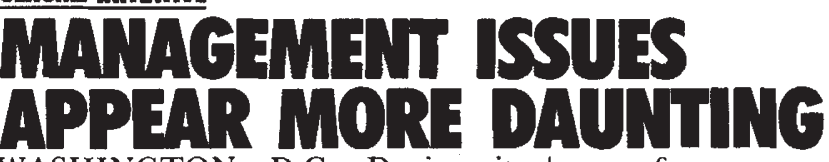

WASHINGTON, D.C.-During its second meeting, the National Institutes of Health (NIH, Bethesda, MD) Program Advisory Committee on the Human Genome struggled with several of the formidable management issues facing researchers planning to map and sequence complex genomes (Bio/Technology 7:223, Mar. '89). Early this year James Watson, director of the Cold Spring Harbor Laboratory (Cold Spring Harbor, NY) and associate director for human genome research at NIH, suggested that each of the human chromosomes be "auctioned" as a way of organizing research efforts into naturally defined units of activity (Bio/Technology 7:559, June ' 89 ). Despite the appeal of this and other management schemes, the advisory committee appears reluctant to set so narrow a course-arguing instead to maintain a "laissez faire" management system for at least the next few years, until technological developments help redirect priorities.

"I think there's merit but substantial hazard" to organizing efforts chromosome by chromosome, says committee member Maynard Olson of the genetics department at Washington University School of Medicine (St. Louis, MO). "I'm personally skeptical that chromosomes will be the unit of analysis, and I'm concerned about the anticompetitive aspect of dividing them up." But committee liaison member Thomas Caskey, chairman of the institute for molecular genetics at Baylor College of Medicine (Houston, TX), says "To get the job done in a timely fashion, we will need a chromosomal organization. Otherwise, we will be doing R\&D with no closure." Watson points out, while "We already have people coming together as chromosome groups, I think it's premature to as- 